\title{
Using PC indices to predict violent GIC events threatening power grids
}

\author{
Peter Stauning* \\ Danish Meteorological Institute, Lyngbyvej 100, 2100 Copenhagen, Denmark
}

Received 7 August 2019 / Accepted 13 January 2020

\begin{abstract}
The aim of the present contribution is to investigate the timing relations between enhancements in the Polar Cap (PC) indices and power grid disturbances related to geomagnetically induced currents (GIC). The polar cap indices, PCN (North) and PCS (South), are based on measurements of geomagnetic variations in the central polar caps. These variations are strongly related to the transpolar convection of plasma and magnetic fields driven by the solar wind. During cases of enhanced merging processes at the front of the magnetosphere and subsequent tailward convection of plasma and embedded magnetic fields, the magnetospheric tail configuration may accumulate excess energy, which upon release may cause violent substorm activity. Earlier reports have disclosed remarkably lengthy intervals, ranging up to several hours, of elevated PC index values preceding GIC-related power grid disruptions. The present investigation has shown that the delays of typically $3-4 \mathrm{~h}$ between increases in the PC indices and GIC-related power grid disturbances are related to displacements of the substorm processes responsible for strong GIC events to subauroral latitudes where vulnerable power grids reside. The results have shown that PC index values remaining above an "alert level" of $10 \mathrm{mV} / \mathrm{m}$ through more than $1 \mathrm{~h}$ indicate a high risk for violent GIC events that may threaten power grids and other vulnerable technical systems. These results support the application of real-time PC indices in space weather monitoring and forecast services.
\end{abstract}

Keywords: Space Weather / polar ionosphere / magnetosphere / solar wind

\section{Introduction}

Geomagnetic variations related to auroral substorm activity may generate Geomagnetically Induced Currents (GIC) in conductive structures. The frequent occurrences of moderate GIC events may have adverse effects causing, among others, enhanced erosion of gas and oil pipelines in auroral and polar regions and degradation of high-voltage transformers by gradual decomposition of insulating materials. See Kappenman (2010) for a review of GIC effects on power grids.

Strong events of GIC in extended high-voltage (HV) power grids may cause tripping of over-voltage or ground current protection circuits whereby HV power lines might be disrupted. During the strongest and long-lasting GIC events the HV transformers could be heated excessively by saturation of the core in one or the other phase by offset of the alternating currents (AC) by additional slowly varying (DC-like) GICs.

Usually, GIC events are not particularly harmful to electric power systems at polar and high auroral latitudes since most of the power supply systems there are based on local power plants. The power grids most exposed to GIC disturbances are those

*Corresponding author: pst@dmi.dk based on electric power production at relatively high latitudes in auroral regions with lengthy high-voltage power lines connecting to consumer networks at lower (subauroral) latitudes. Such constellations are found, among others, in North America and in Scandinavia. Much of the present investigation is based on experiences gained from such power grid systems.

Presently, forecasts of geomagnetic storm conditions that may harm power grids are mostly based on data from satellites (Baker, 2005), for instance, at the L1 position at around 1.5 million $\mathrm{km}$ in front of the Earth. However, the strongest storm events resulting from solar coronal mass ejections (CMEs) are often accompanied by intense high-energy solar proton radiation that may disable the satellite instruments, particularly the plasma detectors providing data on solar wind speed and density. Strongly variable solar wind conditions may also degrade the reliability of the measurements of solar wind parameters. In such cases the satellite-based assessments of the conditions may be incomplete or erroneous (cf. Tables 1 and 4). Ground-based geomagnetic data are then vital for reliable interpretation of the situation and forecasts of potentially harmful events.

The standard Polar Cap (PC) indices, PCN (North) and PCS (South), are based on measurements of geomagnetic variations 
Table 1. List of examined magnetic storm intervals and maxima in $H$ and $\mathrm{d} H / \mathrm{d} t$.

\begin{tabular}{|c|c|c|c|c|c|c|c|c|}
\hline \multirow[t]{2}{*}{ Storm period } & \multicolumn{3}{|c|}{$\operatorname{Max} \mathrm{d} H[\mathrm{nT}]$} & \multicolumn{3}{|c|}{$\operatorname{Max} \mathrm{d} H / \mathrm{dt}[\mathrm{nT} / \mathrm{s}]$} & \multirow[t]{2}{*}{ Power line cuts } & \multirow[t]{2}{*}{ OMNI SW data } \\
\hline & $\mathrm{ABK}$ & LOV & BFE & $\overline{\mathrm{ABK}}$ & LOV & $\overline{\mathrm{BFE}}$ & & \\
\hline 13-14 Jul 1982 & 3155 & 5381 & 4036 & 26.3 & 44.8 & 24.0 & 14 reports & no \\
\hline 13-14 Mar 1989 & 2139 & 3007 & 2969 & 20.9 & 11.6 & 32.8 & 9 reports & no \\
\hline 6-7 Apr 2000 & 771 & 1315 & 1260 & 4.9 & 7.2 & 9.9 & no reports & yes \\
\hline 15-16 Jul 2000 & 1450 & 1252 & 1250 & 5.5 & 6.6 & 10.5 & no reports & yes \\
\hline
\end{tabular}

Note. For the three selected observatories, the maxima in the total horizontal component, $H=\left(X^{2}+Y^{2}\right)^{1 / 2}$, and the time derivative, $\mathrm{d} H / \mathrm{d} t=((\mathrm{d} X /$ $\left.\mathrm{d} t)^{2}+(\mathrm{d} Y / \mathrm{d} t)^{2}\right)^{1 / 2}$, are emphasized in bold letters.

at the magnetic observatories in Qaanaaq (Thule) in Greenland and Vostok in Antarctica in the central northern and southern polar caps, respectively (Troshichev et al., 1988, 2006). These magnetic variations are strongly related to the transpolar convection of magnetic fields and plasma driven by electric fields induced by the encounter of the solar wind and embedded Interplanetary Magnetic Field (IMF) with the Earth's magnetosphere. The effects of the encounters are particularly strong when IMF is southward (negative IMF $B_{\mathrm{Z}}$ ), which enhances the so-called DP2 (Disturbance Polaire type 2) twin-vortex forward convection system with antisunward convection in the central polar caps and sunward return convection at auroral latitudes. The convection is associated with oppositely directed electric (Hall) currents notably in the ionospheric E-region at altitudes of around $120 \mathrm{~km}$. During events of strong northward IMF (NBZ conditions) the transpolar convection could be reversed to generate DP3 reverse convection patterns formed at very high latitudes at the dayside inside weakened DP2 patterns (e.g., Stauning et al., 2002; Lühr et al., 2016). Usually, NBZ conditions are not associated with strong magnetic storm activities.

The DP2 transpolar forward convection carries plasma and embedded magnetic fields from the merging site at the front of the magnetosphere over the polar caps and into the tail region where reconnection of fields emerging from the northern and southern hemisphere may take place. The reconnected fields rooted in the auroral ovals may then be convected back towards the front of the magnetosphere to repeat the so-called Dungey cycle (Dungey, 1961). At low intensities this process may run smoothly with tailward reconnection processes occurring at large distances from the Earth, while at higher intensities the processes may occur in a stepwise manner with reconnection occurring spuriously and at closer distances from the Earth. The stepwise reconnection processes are associated with magnetic disturbances forming the substorm activity processes, which comprise enhanced ionospheric and magnetospheric currents as recorded by the auroral electrojet and ring current indices. The stronger cases of transpolar convection are associated with equatorward displacements of the auroral activities. However, substorm onset, and subsequent poleward progression of substorm activity within an auroral bulge tend to counteract the equatorward displacements (Kamide et al., 1999; Cowley, 2000; Walach et al., 2017).

The shift from steady to stepwise reconnection processes has been studied extensively in order to define an onset level for substorm activity. In terms of the PC index, the substorm onset level is typically found to be close to $2 \mathrm{mV} / \mathrm{m}$ (e.g., Janzhura et al., 2007; Stauning et al., 2008; Troshichev \& Janzhura, 2009; Troshichev et al., 2014). For the cases considered in context of power grid disturbances, the range of relevant PC index values goes far beyond typical substorm onset levels. Thus, substorm-related reconnection processes in the tail region and subsequent poleward progression of auroral activity would be ongoing. However, the substorm activities responsible for GIC events strong enough to harm power grids need to be located at relatively low (subauroral) latitudes. Thus, the transpolar forward convection should remain at a consistently high level (PC index typically above $10 \mathrm{mV} / \mathrm{m}$ ) throughout lengthy time intervals (typically $2-3 \mathrm{~h}$ ) to make the related equatorward displacements dominate over the substorm-related poleward progressions in order be of relevance for power grid disturbances (Stauning, 2013b).

The present contribution shall provide a brief introduction to the derivation of PC indices in Section 2. Next, the available cases of power grid disruptions and their general relations to magnetic disturbances and PC indices are discussed in Section 3. Two example cases with GIC-related power outages are considered in some detail in Sections 4 and 5. The potential application of PC indices to forecast GIC-related power grid failures is discussed in Section 6 while the more general association of enhanced PC index levels with strong and rapid variations in the geomagnetic field is considered in Sections 7 and 8 followed by a summary in Section 9 and conclusions.

\section{The Polar Cap (PC) index}

The basic definition of the Polar Cap (PC) index based on magnetic variations measured in the central polar caps is provided in Troshichev et al. (2006) and may be found elsewhere (e.g., Stauning, 2016). For definition of terms, a short summary is given here.

The relation between polar cap horizontal magnetic field variation vectors, $\boldsymbol{\Delta} \boldsymbol{H}$, projected to an "optimal direction" considered to be perpendicular to the DP2 transpolar plasma flow, and the Kan \& Lee (1979) "merging" (or "geo-effective") electric field in the solar wind has the assumed linear form:

$$
\Delta H_{\mathrm{PROJ}}=\alpha \cdot E_{\mathrm{M}}+\beta
$$

where $\alpha$ is the "slope" (e.g., in units of $\mathrm{nT} /(\mathrm{mV} / \mathrm{m})$ ), while $\beta$ (e.g., in units of nT) is the "intercept" named from a visualized display of the relation. 
The merging electric field values are derived from the solar wind velocity $\left(V_{\mathrm{SW}}\right)$ and the transverse component $\left(B_{\mathrm{T}}\right)$ of the interplanetary magnetic field (IMF), making a polar angle $\theta$ to the Z-direction in the Geocentric Solar Magnetospheric (GSM) coordinate system, by:

$$
E_{\mathrm{M}}=V_{\mathrm{SW}} \cdot B_{\mathrm{T}} \cdot \sin ^{2}(\theta / 2) .
$$

The optimal direction making an angle, $\varphi$, to the polar cap E-W direction and the effective delay, $\tau$, for the propagation of effects from the measuring site for the solar wind parameters forming $E_{\mathrm{M}}$ values to the location of the geomagnetic observations providing $\Delta \boldsymbol{H}$, are both found by optimizing the correlation between $E_{\mathrm{M}}$ and $\Delta H_{\mathrm{PROJ}}$. The calibration parameters, $(\alpha, \beta)$, defined for each moment of the year, are calculated by least squares regression of equation (1) from cases of measured values through an extended epoch, preferably a full solar cycle. From equivalence with $E_{\mathrm{M}}$, the Polar Cap (PC) index is defined by:

$$
\mathrm{PC}=\left(\Delta H_{\mathrm{PROJ}}-\beta\right) / \alpha \quad\left(\approx E_{\mathrm{M}}\right)
$$

This definition of the PC index (Troshichev et al., 1988, 2006) relating index values to solar wind parameters makes the index (in principle) independent of local properties such as time of day, season, and location within either polar cap since such conditions are included in the varying scaling parameters $(\varphi, \alpha, \beta)$. The horizontal geomagnetic field could be represented in either geographic $(X, Y)$ or local magnetic $(H, D)$ components. Data from the standard magnetic observatories for PCN and PCS calculations, Qaanaaq and Vostok, could be complemented by using data from Resolute Bay and Dome-C observatories for added reliability (Stauning, 2018b)

An essential parameter for the calculation of PC index values is the reference quiet level, the so-called Quiet Day Curve (QDC), for each of the two horizontal components, from which the magnetic variation vectors, $\Delta \boldsymbol{H}$, are measured. The calculations performed here are based on the QDC derivation defined in Stauning (2011) and not on the methods described in Janzhura \& Troshichev (2011) since their presentation is affected by grave errors (Stauning, 2013a, 2018a).

\section{Power grid disturbances}

Power grid disturbances related to Geomagnetically Induced Currents (GIC) on High Voltage (HV) power lines have occurred, among others, in Sweden during strong magnetic storms according to reports issued by the Swedish electric power company, "Vattenfallet" (Stauning, 2013b). For a considerable span of years, the magnetic storm conditions in Scandinavia have been recorded by a large array of magnetometer stations including Abisko (ABK) in the auroral zone at invariant latitude (inv.lat.) $=65.50^{\circ}$, and the subauroral observatories Lovö (LOV, inv.lat. $\left.=56.40^{\circ}\right)$, Uppsala (UPS, inv. lat. $=57.00)$ in Mid-Sweden, and Brorfelde (BFE, inv. lat. $=52.90^{\circ}$ ) in Denmark (close to Malmö in Sweden). A list of examined "superstorm" events is presented in Table 1. For the three selected observatories, the maxima in the total horizontal component, $H=\left(X^{2}+Y^{2}\right)^{1 / 2}$, and the time derivative, $\mathrm{d} H / \mathrm{d} t=\left((\mathrm{d} X / \mathrm{d} t)^{2}+(\mathrm{d} Y / \mathrm{d} t)^{2}\right)^{1 / 2}$, are emphasized in bold letters. The maxima in $\mathrm{d} H / \mathrm{dt}$ occur more frequent at the subauroral observatories (LOV, BFE) than at the auroral observatory (ABK). The column OMNI SW data indicates whether data from IMP, WIND, GeoTail, or ACE satellites on solar wind (SW) magnetic fields and plasma parameters are available.

A list of relevant Northern Europe magnetic observatories for which the data are directly addressed in the present work is presented in Table 2 with their geographic coordinates, geomagnetic eccentric dipole (ED) and invariant latitudes, and UT time for midnight $(\mathrm{LMT}=00)$ in local magnetic time (NASA VITMO conversion at $100 \mathrm{~km}$ of height).

A representative example in the Scandinavian region of a substorm with strong temporal gradients and associated with $\mathrm{HV}$ power line disruption is displayed in Figure 1. The northward $(X)$ components are displayed in blue line, the eastward $(Y)$ components in green line. The gradients in the horizontal component $(\mathrm{d} H / \mathrm{d} t)$ derived as the numerical values of the difference vectors between successive 1-min vector samples are shown by the red bars, while the time of disruption of $\mathrm{HV}$ power line circuits is indicated by the black triangles.

The largest depression of more than $2500 \mathrm{nT}$ in the $X$-component of the horizontal magnetic field is seen in Figure 1 at Abisko in Northern Sweden located within the auroral zone that around midnight usually extends from around 62 to 68 degrees invariant latitude (e.g., Xiong \& Lühr, 2014). However, the maximum time variation in the horizontal field is seen at Lövö located in Mid-Sweden equatorward of the usual auroral zone.

It is easily seen that the GIC-related HV power line failure is strictly coincident with the strong gradient $(\mathrm{d} H / \mathrm{d} t=21 \mathrm{nT} / \mathrm{s})$ in the horizontal magnetic field, which is then considered the cause of the power line disruption.

In order to see the GIC-related HV power line failures (Radasky \& Kappenman, 2010) in context with solar activity, Figure 2 presents the occurrences throughout the years 19812015 of 1 -min gradients above $1.0 \mathrm{nT} / \mathrm{s}(60 \mathrm{nT} / \mathrm{min})$ in the horizontal magnetic field for each of the three selected locations, Abisko, Lövö/Uppsala, and Brorfelde. (Note that the magnetic observations in Lövö were terminated in 2004 but continued at the nearby observatory in Uppsala). The magnitude of the gradients are shown by the bars on the left scale while their signs are shown by the colours, red for positive, and blue (on top) for negative deviations. Solar activity as recorded by the monthly average sunspot numbers is displayed in magenta line on the scale to the right. Times of HV power line disruptions are displayed by the black triangles at the time line.

It is evident from the displays in Figure 2 that the power grid disturbances are associated with coincident events of large gradient values. The coincidences are particularly clear for the measurements made at Lövö/Uppsala and Brorfelde at subauroral latitudes where all cases of power line disruptions are associated with gradients above $10 \mathrm{nT} / \mathrm{s}$ in the horizontal magnetic field. Conversely, it appears that almost all cases of $\mathrm{d} H / \mathrm{d} t>10 \mathrm{nT} / \mathrm{s}$ at subauroral latitudes are associated with $\mathrm{HV}$ power line cuts all of which, contrary to the Quebec event on 13 March 1989 , caused no apparent permanent damage on the power grid circuits.

There are no magnetic data from Vostok magnetic observatory for any of the storm events associated with GIC-related HV power line failures reported here. Hence, for these cases the PC 
P. Stauning: J. Space Weather Space Clim. 2020, 10, 3

Table 2. Relevant Northern Europe magnetic observatories and Malmö (not observatory).

\begin{tabular}{|c|c|c|c|c|c|c|}
\hline Observatory & Acronym & Latitude & Longitude & ED latitude & Inv. latitude & 00 LMT \\
\hline Dombaas & DOM & $62.07^{\circ} \mathrm{N}$ & $9.11^{\circ} \mathrm{E}$ & $59.72^{\circ}$ & $59.70^{\circ}$ & 22:16 UT \\
\hline Uppsala & UPS & $59.90^{\circ} \mathrm{N}$ & $17.35^{\circ} \mathrm{E}$ & $56.63^{\circ}$ & $57.00^{\circ}$ & 21:50 UT \\
\hline Lövö & LOV & $59.35^{\circ} \mathrm{N}$ & $17.83^{\circ} \mathrm{E}$ & $56.04^{\circ}$ & $56.40^{\circ}$ & $21: 50 \mathrm{UT}$ \\
\hline Brorfelde & $\mathrm{BFE}$ & $55.63^{\circ} \mathrm{N}$ & $11.67^{\circ} \mathrm{E}$ & $53.18^{\circ}$ & $52.90^{\circ}$ & 22:17 UT \\
\hline Hel & HLP & $54.61^{\circ} \mathrm{N}$ & $18.82^{\circ} \mathrm{E}$ & $51.30^{\circ}$ & $51.45^{\circ}$ & 21:52 UT \\
\hline
\end{tabular}

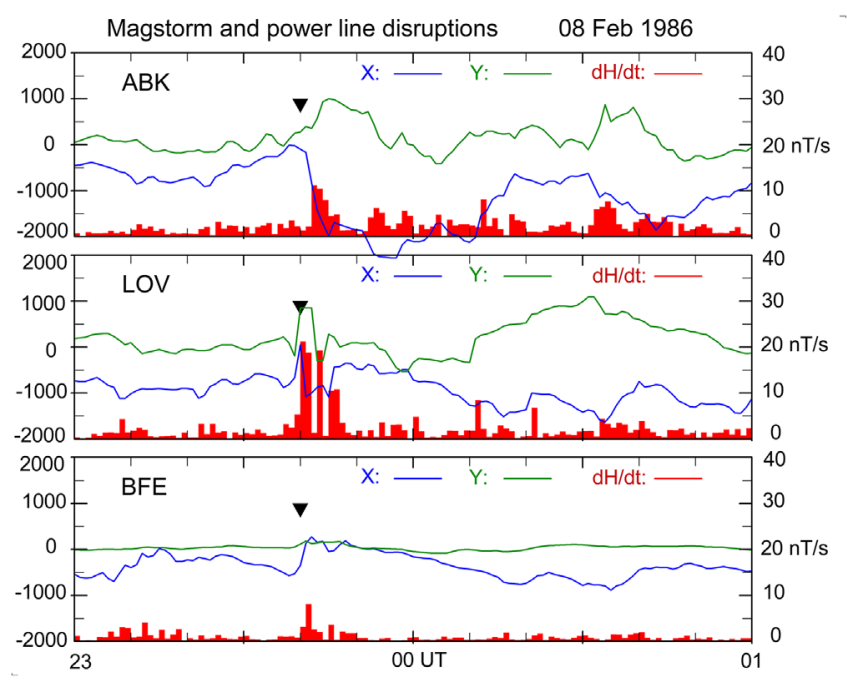

Fig. 1. Representative example of the horizontal components $(X, Y)$ during a substorm with strong gradients displayed by red bars. Max. $\mathrm{d} H / \mathrm{d} t=21 \mathrm{nT} / \mathrm{s}$. The onset time of GIC-related HV power line disruption is marked by the black triangles.

index conditions rely on PCN index values instead of the possibly more representative PCC index combining PCN and PCS (Stauning, 2007). For the 11 events of power grid failures, the median PCN values through $4 \mathrm{~h}$ before and $4 \mathrm{~h}$ after the time of reported power line disruptions are displayed in Figure 3 (from Stauning, 2013b).

From Figure 3 it is seen that almost all cases of power line disruption are preceded by $3-4 \mathrm{~h}$ of PCN index values elevated above an "alert" level of $10 \mathrm{mV} / \mathrm{m}$. This feature indicates that the PC indices could be used in space weather forecast services to issue warnings of possible GIC-related power grid problems, when the PC index values have been elevated above this alert level for one or more hours.

\section{The 30 October 2003 Malmø power outage event}

This section shall examine the 30 October 2003 power outage event in Malmö, Sweden, with onset at 20:07 UT. Malmö is located in the southern part of Sweden and receives electric power, among others, from the hydro-electric power generator plants in northern Sweden via around $1200 \mathrm{~km}$ of $\mathrm{HV}$ power lines (cf. Fig. 5). The specific cause of the disruption was the triggering of the line protection system by an elevated amount of harmonics in the $50 \mathrm{c} / \mathrm{s}$ voltages probably caused by transformer saturation related to GIC currents.

PCN index values and further relevant geomagnetic indices and data are displayed in Figure 4.

The top field of Figure 4 displays the PCN index values throughout 12:00 to 24:00 UT on 30 October 2003, which encompasses the power grid failure in Malmö starting at 20:07 UT. Since 12:30 UT the PCN indices have displayed values above $5 \mathrm{mV} / \mathrm{m}$. From 17:00 and through the disruption event at 20:07 the PCN indices, except for a short interval at around 18:30 UT, remained above alert level $(10 \mathrm{mV} / \mathrm{m})$ marked by a dashed red line.

The next lower fields displays the standard auroral electrojet indices AU, AL, and AE, and also the SuperMag SMU and SML auroral electrojet indices based on an extended array of observatories (Gjerloev, 2012). A suggested grouping of specific events (subst.\#1, subst.\#2, subst.\#3) of auroral activities is shown in the field below the auroral electrojet indices.

Further lower fields display measured values of the horizontal geomagnetic component $(H)$ counted positive when northward $(X>0)$ and with the regular daily variation subtracted. The black triangle at the time line indicates the time (20:07 UT) of HV power line disruption. The auroral activity displayed in Figure 4 might be seen to comprise an interval of rather steady auroral electrojet activity between 12:30 and 16:00 UT, and three separate substorm events. All auroral electrojet indices as well as the magnetic recordings from Abisko (65.50 inv.lat.) indicate the occurrence of a moderate substorm at around 16:30 to 18:20 UT which, however, appears to have little effects at lower latitudes. The next substorm with multiple onsets or intensifications of which the first appeared at Abisko at 18:30 UT reached lower latitudes in successive steps. At the second onset at 19:10 UT of this substorm, the activity reached Lerwich (58.56 ${ }^{\circ}$ inv.lat.), while at the third onset shortly before 20:00 UT, the activity reached all the way equatorward to Hartland (48.96 ${ }^{\circ}$ inv.lat.). A third substorm is seen in Figure 4 at 21:10 $-22: 30$ UT at subauroral latitudes. It had a particularly strong and sharp onset at 21:15 UT at Lerwick.

It might be worth noting that the AL index tracks the recordings at Abisko (one of the standard AE index observatories) throughout the three substorm events discussed here. The AU and AL indices track the SMU and SML indices, respectively, through the steady interval and the first substorm interval. In the second substorm interval the AL index tracks the SML index 

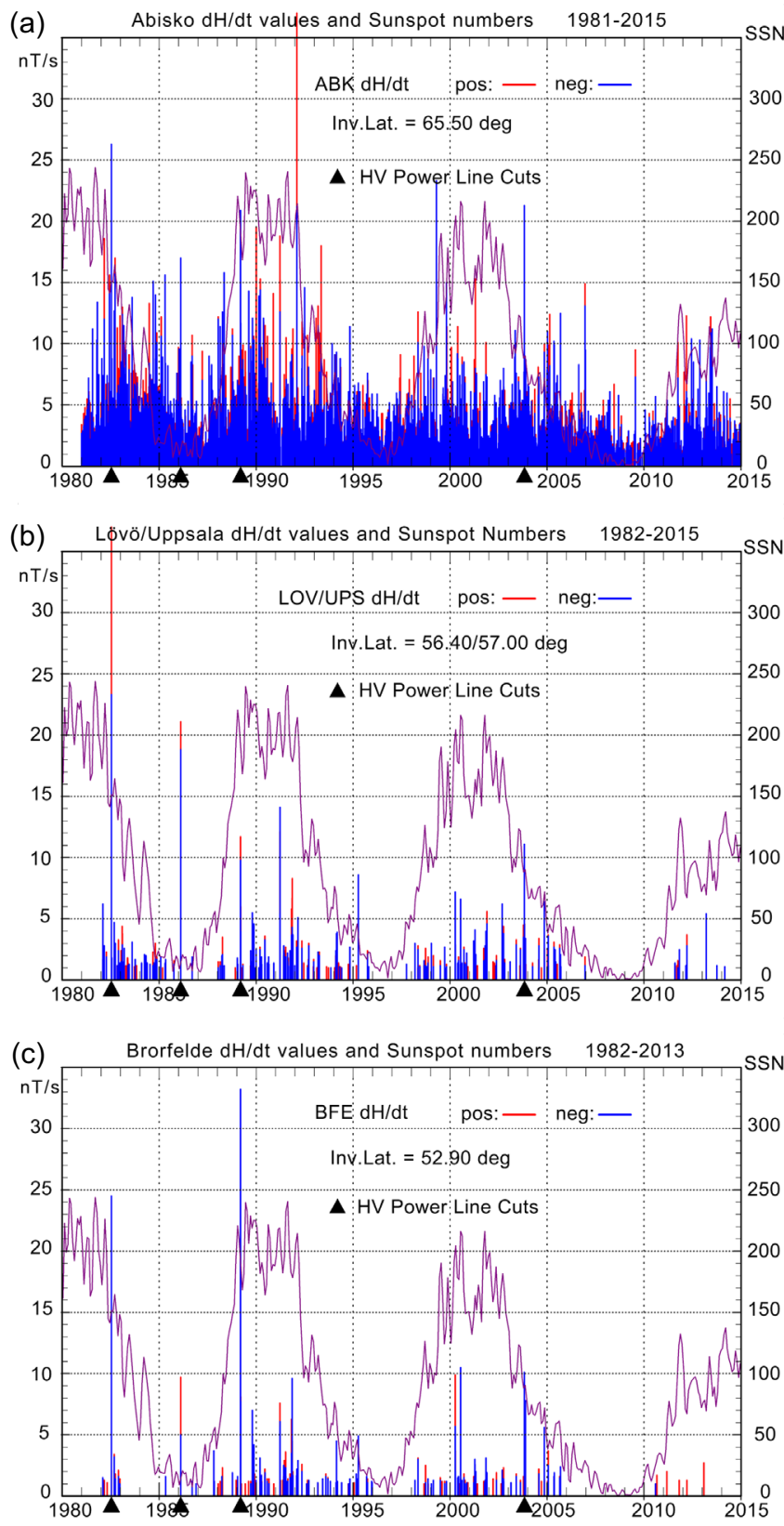

Fig. 2. (a) Gradients (nT/s) in the horizontal magnetic field measured at Abisko. Negative gradients are plotted in blue line on top of the positive gradients in red. Monthly sunspot numbers (v2.0) on right scale are plotted in magenta line. Times of HV power line disruptions are indicated by the black triangles. (b) and (c) Corresponding plots for gradients in Lövö/Uppsala and Brorfelde magnetic data.

while the AU and SMU indices are quite different. In the third substorm interval there is no match between the AU and SMU indices and also no match between AL and SML. The lack of match between the standard and the SuperMag electrojet indices, most likely, was caused by the equatorward shift of auroral activity. The extended latitudinal coverage of the observatory basis for the SuperMag auroral electrojet indices compared to the observatory basis for the standard electrojet indices made it possible to record auroral activity farther equatorward of the usual auroral zone by using SM indices.

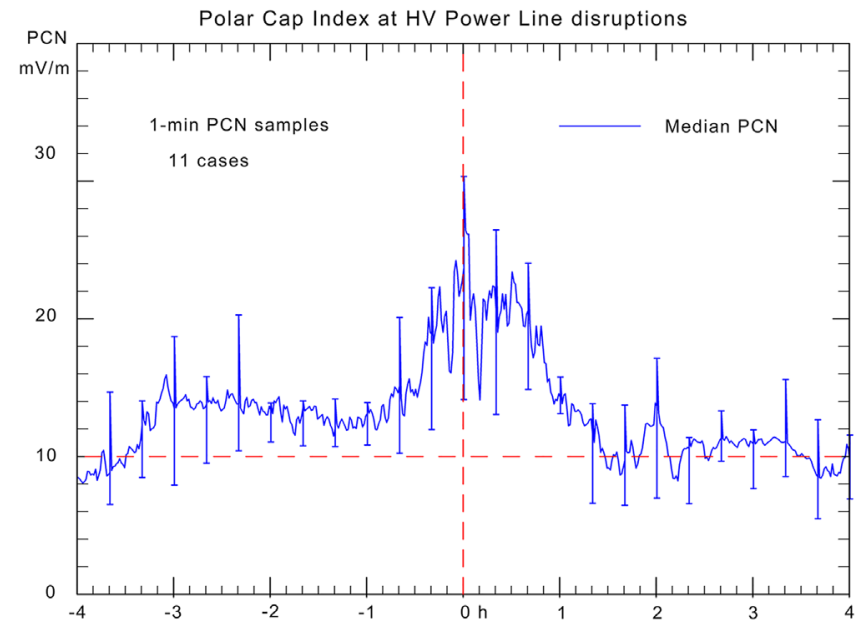

Fig. 3. Median PCN index values relative to times of HV power line disruption events. Error bars indicate standard deviation. (from Stauning, 2013b)

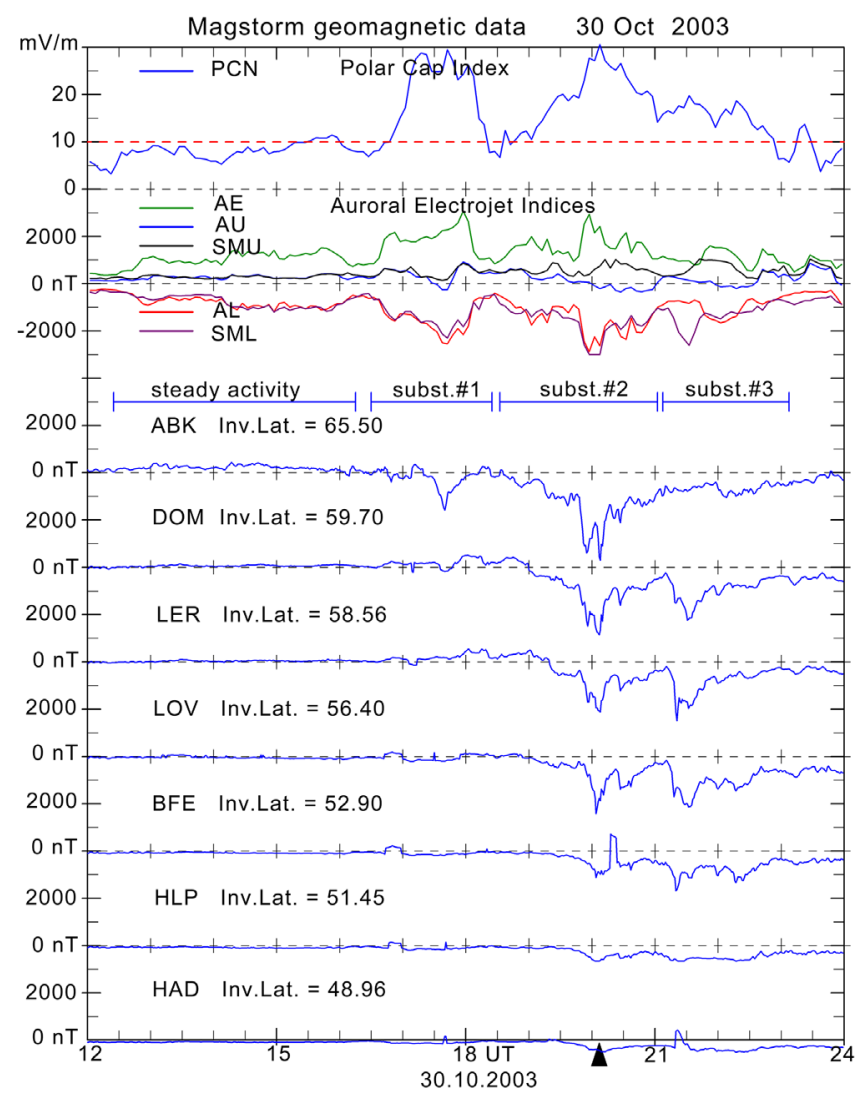

Fig. 4. PCN index displayed in top field. Auroral electrojet indices AU, AL, and AE and SuperMag SMU and SML indices in second and third field. Next lower fields display recordings of the variations in the horizontal geomagnetic component counted positive when northward for a series of observatories ordered from top at decreasing latitudes. The black triangle marks HV power line disruption.

Figure 5 (modified from Stauning, 2013b, using further magnetic data) displays recordings of the magnetic variation vectors at an extensive array of observatories (42) in Northern 


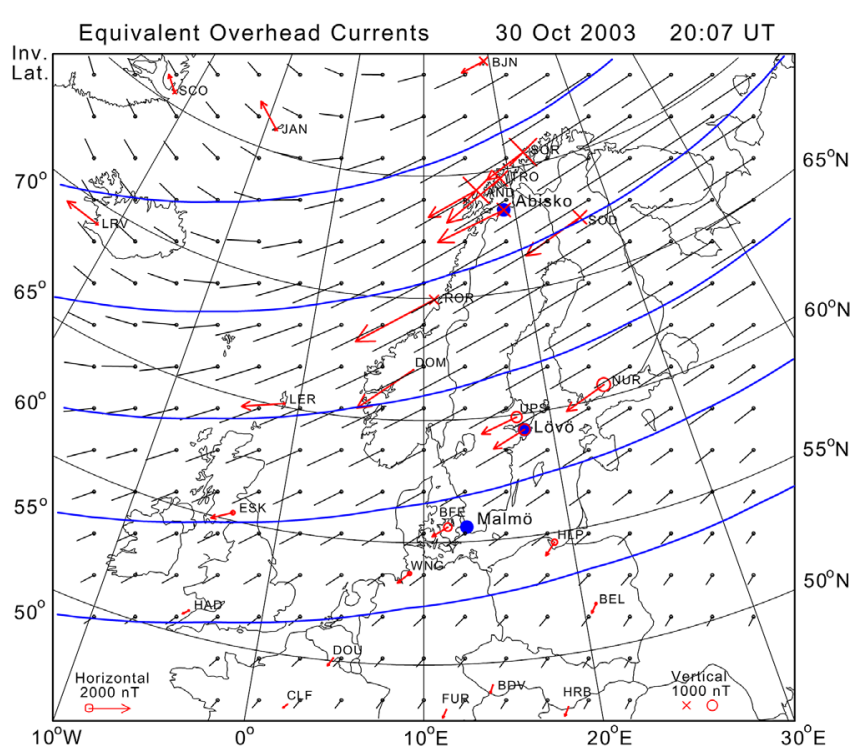

Fig. 5. Display of magnetic deflections measured at a range of observatories. The horizontal variation vectors have been rotated $90^{\circ}$ $\mathrm{CW}$ to illustrate overhead current directions. The display of measured magnetic vectors has been supplemented by interpolated values of the horizontal vector component in a regular pattern. (modified from Stauning, 2013b).

Europe, Svalbard, Iceland and Greenland. Some of them are shown in the Northern Europe contour map with the grid of geographic latitude circles on the scale to the right and longitude lines on the bottom scale. The geomagnetic latitudes are indicated by the meridians in solid blue line every $5^{\circ}$ on the left scale. The red arrows display the magnitudes of the measured horizontal magnetic components with the direction rotated clockwise $(\mathrm{CW})$ by $90^{\circ}$ in order to indicate the direction of the overhead currents responsible for the geomagnetic variations.

The overhead currents are displayed by their related magnetic effects at ground level, that is, in nT. They might be converted into current strengths $[\mathrm{A} / \mathrm{m}]$ by using assumptions on the distribution of Hall and Pedersen conductivities (e.g., Popov et al., 2001). The circles and crosses display the upward or downward vertical magnetic components. The black bars with their starting points (dots) placed in a regular pattern have been derived by bi-variate interpolation of magnetic vectors including also data from observatories outside the displayed region. Note the positions of Abisko, Lövö/Uppsala and Brorfelde magnetic observatories. The position of Malmö in Southern Sweden, close to Brorfelde, has been marked by a blue dot.

It is possible to illustrate the temporal and geographical development of the substorm-associated geomagnetic variations with series of such displays. The temporal development of the substorm activity is illustrated in Figure 6 of the latitudinal profile of equivalent current intensities at Uppsala (Lövö) magnetic longitude. Like for the vector diagram in Figure 5, the overhead equivalent current strengths are displayed in units of nT using their related magnetic effects at ground level.

Figure 6 displays the temporal development throughout 16:00 to 22:00 UT on 30 October 2003 of the equivalent overhead current density profile along Uppsala (Lövö) magnetic longitude. For simplicity, the eccentric dipole (ED) coordinate

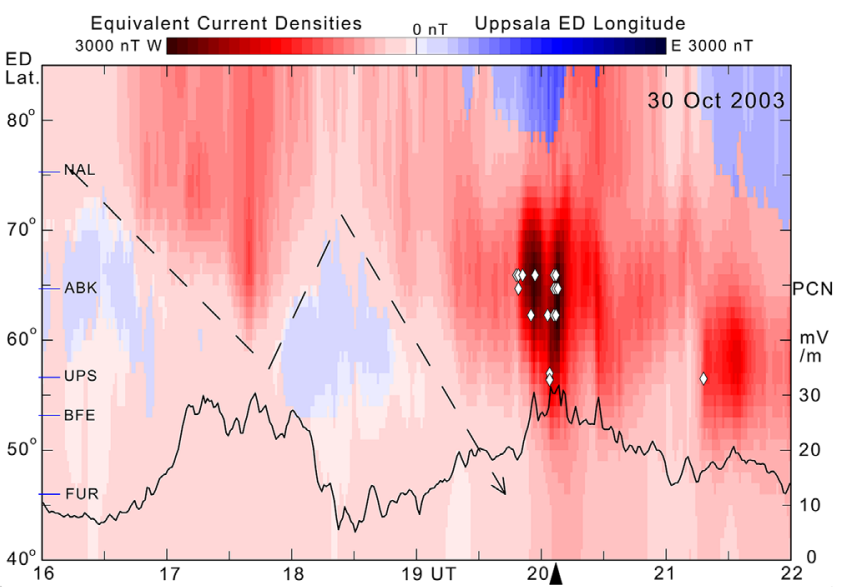

Fig. 6. Temporal development of equivalent overhead current density profile at Uppsala (Lövö) magnetic longitude. At the left latitude scale the latitudes of a few relevant observatories are marked. Westward currents are marked by red colours in shades to indicate current intensities. Eastward currents by blue colours. The curve in full black line displays PCN index values with their scale to the right. The white diamonds indicate events of magnetic variations steeper than $10 \mathrm{nT} / \mathrm{s}$. The dashed broken line indicates movements of current systems. The black triangle marks the power line cut.

system was used here (cf. Table 2). The latitude scale is shown to the left. Along the scale, a few relevant observatories have been marked according to their magnetic latitudes. Westward overhead current is displayed in red colours in shades corresponding to their equivalent current strength (ground magnetic effect). Eastward currents are shown in blue colour shades. PCN index values are displayed by the solid black line referring to the scale to the right. The white diamonds indicate events of magnetic variations with gradients steeper than $10 \mathrm{nT} / \mathrm{s}$, while the black triangle marks the power line disruption.

Local magnetic midnight at Uppsala is at around 21:50 UT. Thus, the display in Figure 6 illustrates the current systems at the pre-midnight "Harang discontinuity" dominated by the westward substorm electrojet currents in the "auroral bulge" of the substorm expansion phase (e.g., Cowley, 2000; Gjerloev $\&$ Hoffman, 2014). The dashed broken line indicates the movements of the equatorward border of the active substorm electrojet.

In Figure 6 at hours between 16:00 and 17:00 UT the transpolar currents associated with the antisunward convection is seen as a westward overhead polar current system (red colour) merging with the substorm electrojet westward currents, while the eastward return currents at lower latitudes in the late evening part of the auroral oval is seen in blue colours. As the PCN index increased between 17:00 and 18:00 UT, the substorm and polar cap current systems expanded to lower latitudes while their geomagnetic effects dominated over those of the weak eastward auroral currents. The substorm activity between 17:30 and 18:20 UT, during the first of the three substorms discussed with relation to Figure 4, and the weakening of transpolar convection intensities indicated by the decrease in PCN index values made the substorm electrojet current system retreat poleward. Just after 1820 UT the PCN index values (the transpolar convection) increased again while the substorm activity, 
Table 3. Quebec location and relevant magnetic observatories in and around Canada.

\begin{tabular}{|c|c|c|c|c|c|c|}
\hline Observatory & Acronym & Latitude & Longitude & ED latitude & Inv. latitude & 00 LMT \\
\hline Fort Churchill & $\mathrm{FCC}$ & $58.76^{\circ} \mathrm{N}$ & $265.91^{\circ} \mathrm{E}$ & $69.27^{\circ}$ & $69.03^{\circ}$ & 06:34 UT \\
\hline Glenlea & GLN & $49.65^{\circ} \mathrm{N}$ & $262.88^{\circ} \mathrm{E}$ & $56.35^{\circ}$ & $60.04^{\circ}$ & 06:45 UT \\
\hline Ottawa & OTT & $45.40^{\circ} \mathrm{N}$ & $284.45^{\circ} \mathrm{E}$ & $52.20^{\circ}$ & $56.25^{\circ}$ & 04:55 UT \\
\hline St. Johns & STJ & $47.60^{\circ} \mathrm{N}$ & $307.32^{\circ} \mathrm{E}$ & $53.09^{\circ}$ & $54.04^{\circ}$ & 03:01 UT \\
\hline Fredericksburg & FRD & $38.20^{\circ} \mathrm{N}$ & $282.63^{\circ} \mathrm{E}$ & $47.50^{\circ}$ & $49.49^{\circ}$ & 05:08 UT \\
\hline
\end{tabular}

as seen in the auroral electrojet indices, was weak. In consequence, the substorm electrojet current system was now displaced equatorward as marked by the dashed line in Figure 6.

At around 20:00 UT the substorm-related currents at the second of the substorms discussed with relation to Figure 4 created a surge or whirl of strong westward substorm electrojet currents also seen in Figure 5 at magnetic latitudes between $55^{\circ}$ and $70^{\circ}$. Upon successive substorm onsets at decreasing latitudes (cf. Fig. 4) shortly before 20:00 UT, a poleward progressing series of substorm onsets with strong gradients $(\mathrm{d} H /$ $\mathrm{d} t>10 \mathrm{nT} / \mathrm{s}$ ) is displayed just after 20:00 UT by the sequence of white diamonds in Figure 6 starting at or equatorward of Uppsala (inv.lat. 57.00) and Lövö (inv.lat. 56.40 $)$ and extending poleward of Abisko (inv.lat. $65.50^{\circ}$ ). The GICs related to the sharp substorm onsets expanding poleward over a distance possibly exceeding $1000 \mathrm{~km}$ from Southern to Northern Sweden (i.e. in the direction of the connecting HV power lines), most likely, was the cause of the power outage in Malmö at 20:07 UT.

A plot (not shown) similar to Figure 6 of the latitudinal profile of the geomagnetic vertical $(Z)$ component along Uppsala magnetic longitude places the location of the strongest overhead currents at the outage event (20:07 UT) at $60^{\circ}$ invariant magnetic latitude between upward $Z$-component values to the south and downward values to the north. This position is in agreement with the display in Figure 5, where the upward Z-components are marked by circles, e.g., at Lövö and Nurmijärvi (inv. lat. $\approx 58^{\circ}$ ), and downward $Z$-component values by crosses, e.g., at Rorvik and Sodankylä (inv.lat. $\approx 65^{\circ}$ ).

\section{Power outage event in Quebec on 13 March 1989}

Conditions corresponding to those of the Malmö outage event on 30 October 2003 were observed in relation to the power outage event in Quebec on 13 March 1989 starting at 07:44 UT (02:44 EST). The magnetic variations at the event were recorded by an array of observatories in and around Canada of which a selection is presented in Table 3 with their geographic coordinates, magnetic latitudes and UT time for local magnetic midnight.

PCN values for 13 March 1989 at 00:00 to 12:00 UT, which encompasses the power outage event are shown in the upper field of Figure 7. The figure also presents in the format of Figure 4 the auroral electrojet indices AU, AL, AE, SMU, and SML on the scale to the left, as well as the ring current indices Dst, Asy-H and Sym-H on the right scale. Recordings of the total horizontal magnetic components counted positive when northward measured from selected observatories are displayed in the lower fields organized according to their latitudes. (Note that the magnetic recordings had to be handled with care due to irregularities in the original data)

It is seen from Figure 7 that the PCN index exceeds the alert level $(10 \mathrm{mV} / \mathrm{m})$ marked by the dashed red line at 02:00 UT and remained close to or above this level throughout the following $6 \mathrm{~h}$ including the onset of the GIC-related power outage at 07:44 UT. It is also seen that neither the standard AE nor the SuperMag SM auroral electrojet indices showed any particular deflection (all well below $1000 \mathrm{nT}$ ) preceding the time of the power outage. The magnetic recordings at Ottawa and (in particular) Glenlea shown in Figure 7 displayed the sharp onset at 07:42 UT of a poleward expanding substorm. The largest recorded gradient was $14.5 \mathrm{nT} / \mathrm{s}$ observed at Glenlea at 07:45 UT shortly after the onset of the $2000 \mathrm{nT}$ deep depression in the horizontal magnetic field.

It is worth noting that neither the AL nor the SML electrojet indices recorded the large bays at Glenlea and Ottawa since their latitude coverage did not include these subauroral locations. This problem is similar to the corresponding situation for the Malmö 2003 event discussed in Section 4. In spite of the rather mild auroral electrojet indices, a whirl of strong substorm ionospheric electrojet currents actually swept over Canada at that time as displayed in Figure 8 in the format of Figure 5. At Quebec the currents were westward. The equivalent current vectors based on geomagnetic recordings are displayed by red arrows for the observatories located within the region shown in the map in Figure 8 of the Eastern part of North America. In addition, the display presents interpolated overhead (equivalent) current vectors by the bars extending from dots placed in a regular pattern. The interpolated current vectors have been derived by bivariate interpolation of data from 39 observatories located within and around Canada.

The (equivalent) ionospheric current vectors are here displayed at 07:46 UT just after the power outage at 07:44 UT since the build-up of these currents included the fast time variations that probably caused the GIC-related power grid failure at Quebec. Like for the Malmö event at 20:07 UT on 30 October 2003, the location of the strongest horizontal currents are placed between upward magnetic vertical $(Z)$ components (marked by a circle at Ottawa) south of Quebec and downward vertical components (marked by crosses at Porte de la Balaine and Glenlea) to the north.

Like mentioned at Figure 5, the combined geographical and temporal development of the event could be illustrated by a 


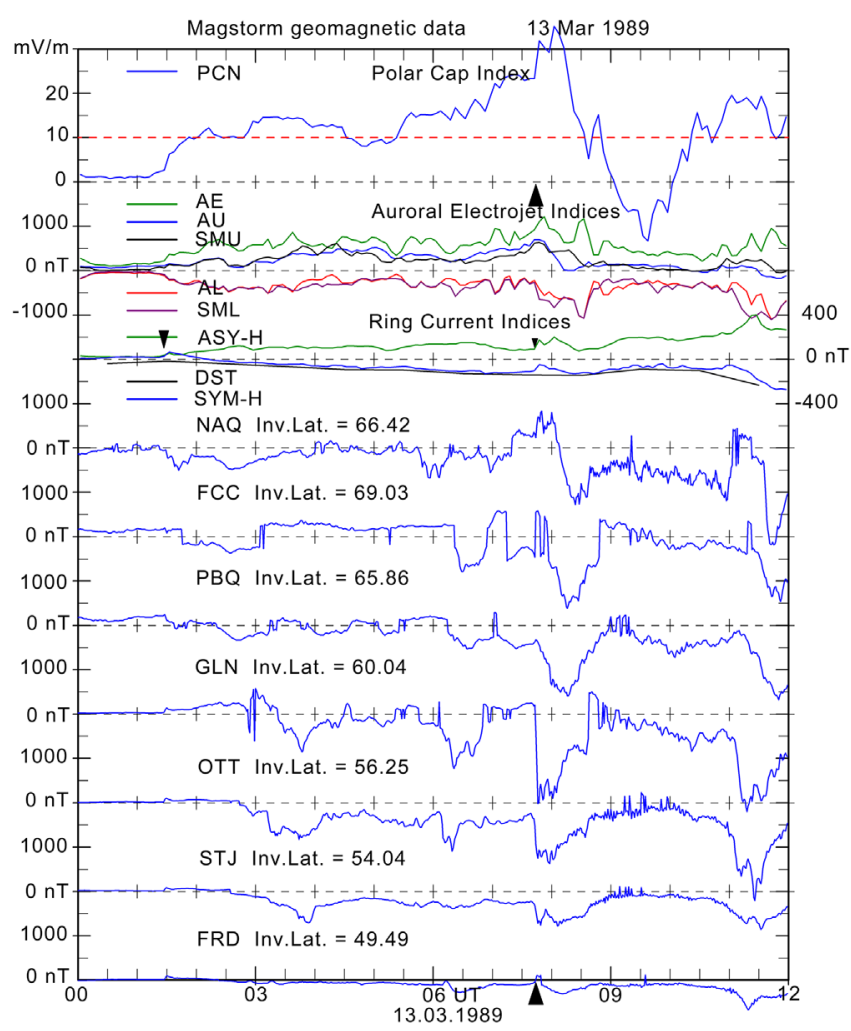

Fig. 7. Geomagnetic indices and magnetic recordings in the format of Figure 4 for 00 to 12 UT on 13 March 1989. The times and amplitudes of SSCs at 01:27 UT (60 nT) and 07:43 UT (11 nT) are indicated by the positions and sizes of downward triangular marks in the ASY-H field.

series of diagrams like Figure 8. Instead, the temporal development is here illustrated by the latitudinal profile of overhead (equivalent) currents along Quebec ED longitude at around the time of the power outage at 07:44 UT on 13 March 1989 as displayed by Figure 9 in the format of Figure 6.

Figure 9 displays the latitudinal profile of equivalent overhead current intensities along Quebec magnetic (ED) longitude. Westward currents are shown in red shades. Eastward currents in blue. Substorm magnetic gradients (interpolated at Quebec) steeper than $5 \mathrm{nT} / \mathrm{s}$ are shown by the white diamonds. Along the latitude scale to the left, selected observatories have been marked by their latitudes. The curve in solid black line displays $\mathrm{PCN}$ index values on the right scale.

Magnetic midnight occurs at around 04:33 UT at Quebec. In the late evening hours at 01:30 to 03:30 UT, the PCN values have increased above the alert level $(10 \mathrm{mV} / \mathrm{m})$. The border between the eastward currents at latitudes within the auroral oval and the westward substorm electrojet currents had moved equatorward as indicated by the dashed arrow-headed line. It appears that the westward substorm auroral electrojet currents remained at ED latitudes of around $52^{\circ}-55^{\circ}$ close to that of Quebec between the latitudes of Ottawa and Glenlea. Such currents would most often be positioned poleward of $60^{\circ}$ magnetic latitude bridging the gap between the evening and morning auroral oval across midnight (Xiong \& Lühr, 2014). The unusually low latitudes for the enhanced substorm auroral currents indicate strongly stressed, unstable conditions. In the present

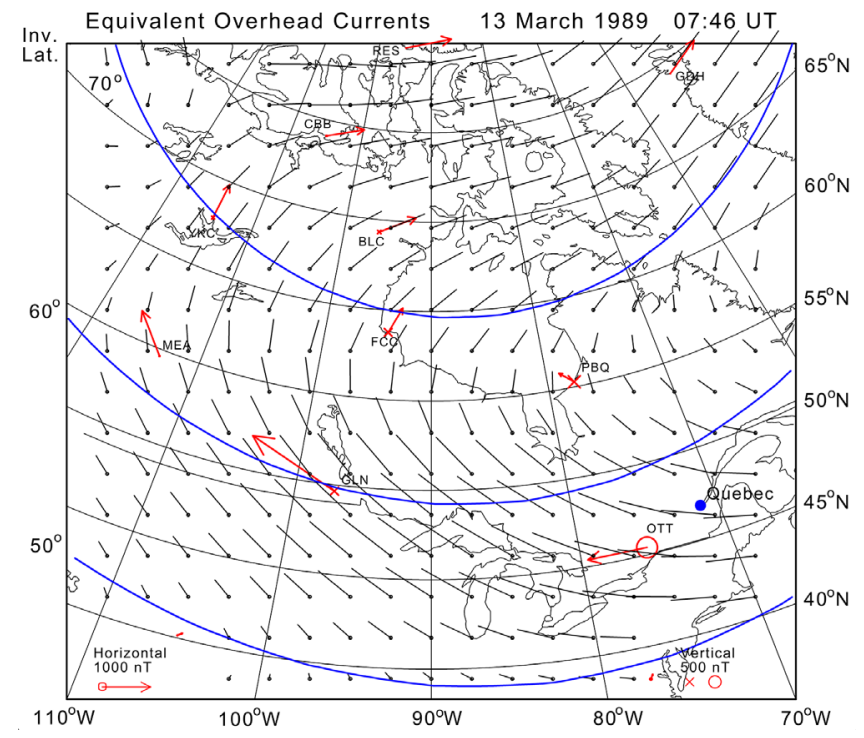

Fig. 8. Whirl of overhead ionospheric currents over eastern Canada on 13 March 1989 at 07:46 UT in the format of Figure 5.

case, these conditions were maintained through several hours by the enhanced transpolar convection implied by the high PCN values and the moderate return flow associated with relatively weak auroral substorm activity indicated by the low auroral electrojet index values. At 07:42 UT, a couple of hours past midnight, the stresses were unloaded in a strong poleward expanding substorm with sharp onset, which was most likely the cause of the GIC-related power outage at Quebec starting at 07:44 UT on 13 March 1989.

\section{Discussions}

The enhanced PCN levels maintained during several hours preceding the power grid disruptions are among the common features of the two cases of GIC-related power outage events considered here. The occurrences of poleward progressing substorms with sharp onsets and strong westward electrojet currents starting out from unusually low subauroral latitudes are another common feature.

In order to move the westward substorm electrojet to subauroral latitudes, the transpolar forward convection should be strong and dominate over tail recombination processes through a substantial time interval. The cases considered here, displayed in Figures 6 and 9, show that it lasts 2-3 h with PC index values exceeding the alert level $(10 \mathrm{mV} / \mathrm{m})$ to move the auroral regions sufficiently equatorward and load enough energy into the tail configuration (Kamide et al., 1999) to cause the really strong substorms that may generate strong and harmful GICs at subauroral latitudes like Mid-Sweden or the Quebec region. Adding some time for the triggering to happen results in the typical 3-4 h delay between reaching alert level and onset of substorm activity causing power grid failures.

It is probably not possible to derive a functional relation between the merging electric field and the position and strength of the dynamic westward substorm electrojet currents. They are located at the transition between the morning and evening 


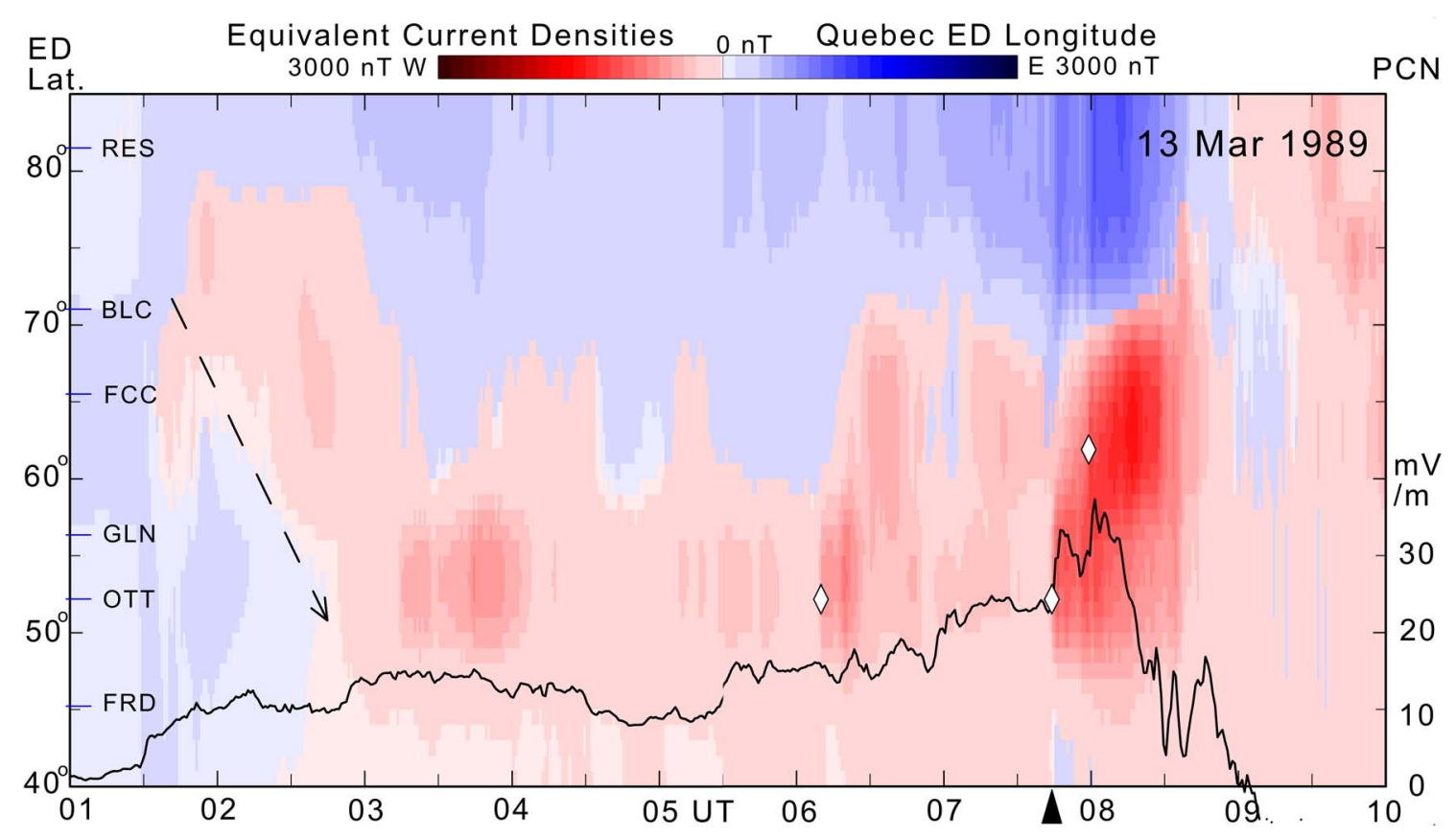

Fig. 9. Equivalent overhead current profile at Quebec magnetic longitude throughout 01:00 to 10:00 UT on 13 March 1989 in the format of Figure 6. The overhead current intensity scales are the same for the two figures. Substorm magnetic gradients steeper than $5 \mathrm{nT} / \mathrm{s}$ (interpolated at Quebec longitude) are shown by the white diamonds. PCN index values are displayed by the solid black curve. The black triangle marks the time of power outage.

Table 4. Solar wind parameters for cases of persistent strong transpolar convection (large PC indices) throughout 1981-2016.

\begin{tabular}{|c|c|c|c|c|c|c|c|c|c|}
\hline $\begin{array}{l}\mathrm{PCN} \text { range } \\
{[\mathrm{mV} / \mathrm{m}]}\end{array}$ & PCN [cases] & $\begin{array}{c}\text { Avr. PCN } \\
{[\mathrm{mV} / \mathrm{m}]}\end{array}$ & $E_{\mathrm{M}}$ [cases] & Avr. $B_{\mathrm{Y}}[\mathrm{nT}]$ & Avr. $B_{\mathrm{Z}}[\mathrm{nT}]$ & $\begin{array}{c}\text { Avr. } V_{\mathrm{SW}} \\
{[\mathrm{km} / \mathrm{s}]}\end{array}$ & $\begin{array}{c}\text { Avr. } D_{\text {SW }} \\
{\left[\mathrm{cm}^{-1}\right]}\end{array}$ & $\begin{array}{l}\text { Avr. } E_{\mathrm{M}} \\
{[\mathrm{mV} / \mathrm{m}]}\end{array}$ & $\begin{array}{l}\text { Avr. } E_{\mathrm{M}} \\
{[\mathrm{mV} / \mathrm{m}]^{*}}\end{array}$ \\
\hline $10<\mathrm{PCN}<12$ & 30 & 11.4 & 14 & 9.2 & -9.2 & 738 & 6.1 & 8.8 & 30.7 \\
\hline $12<\mathrm{PCN}<15$ & 86 & 13.5 & 46 & 9.3 & -13.9 & 705 & 12.4 & 12.4 & 38.2 \\
\hline $15<\mathrm{PCN}<20$ & 51 & 16.9 & 23 & 8.8 & -17.1 & 683 & 10.6 & 12.9 & 37.7 \\
\hline
\end{tabular}

auroral regions. A comprehensive description of the statistical positions of the auroral oval through all local hours including the midnight region is provided in Xiong et al. (2014) and extended into a model by Xiong \& Lühr (2014). In their work they use a coupling function, $E_{\mathrm{M}}$, , different from the Kan \& Lee (1979) merging electric field, $E_{\mathrm{M}}$, in $\mathrm{mV} / \mathrm{m}$ used here for calibration of the PC indices (cf. Eqs. (1)-(3)). The new coupling function was derived by Newell et al. (2007) according to:

$$
E_{\mathrm{M}}{ }^{\prime}=0.001 \cdot V_{\mathrm{SW}^{4 / 3}} \cdot\left(B_{Y^{2}}+B_{Z^{2}}\right)^{1 / 3} \cdot \sin (\theta / 2)^{8 / 3} .
$$

The composition of $E_{\mathrm{M}}$ ' with $V_{\mathrm{SW}}$ in $\mathrm{km} / \mathrm{s}$ and $B$ in $\mathrm{nT}$ in odd powers leaves $E_{\mathrm{M}}$ ' no position in the standard MKSA system of units but is considered equivalent to $E_{\mathrm{M}}$ anyway. In Table 4, the unit for $E_{\mathrm{M}}$ ' is just named $[\mathrm{mV} / \mathrm{m}]^{*}$.

In order to provide an impression of the typical ranges of solar wind parameters for the cases of strong transpolar convection, all cases of $60 \mathrm{~min}$ contiguous PCN $>10 \mathrm{mV} / \mathrm{m}$ throughout the years 1981 to 2016 have been considered. The event times are noted and the PCN averages through the $60 \mathrm{~min}$ have been calculated. These samples, which are separated by at least one hour, have been subdivided in PCN intervals 10-12, 12-15, and $15-20 \mathrm{mV} / \mathrm{m}$. The number of samples within each interval and their averages are displayed in Table 4 along with the corresponding number of available solar wind $\left(E_{\mathrm{M}}\right)$ cases and solar wind parameters (OMNI data) averaged over the same intervals shifted by the Bow Shock Nose to Polar Cap delay (25 $\mathrm{min})$

The solar wind quantities in Table 4, derived with time shifts of 25 min from Bow Shock Nose (BSN) to polar cap, should be considered with some reservation. The parameters have been measured during extreme and often strongly fluctuating conditions contrary to the polar cap indices that are exposed to a "natural" smoothing resulting from the "inertia" by delays in rise and decay properties (Stauning et al., 2008). However, some general inferences can be made.

The numbers of cases with available solar wind parameters are only half the numbers of cases with available PCN values mostly because satellite plasma detectors are often disabled by hard solar radiation during the strong storm events. The IMF $B_{\mathrm{Z}}$ quantity is the most important term among the controlling parameters in the solar wind. The average PCN values agree fairly well with the $E_{\mathrm{M}}$ parameter values (which they should). The average values of the Newell et al. (2007) coupling parameter $E_{\mathrm{M}}$ ' are around three times the Kan \& Lee (1979) merging electric field, $E_{\mathrm{M}}$, values.

The latter relation makes it possible to enter the Xiong \& Lühr (2014) auroral model. Depending on the activity level, 
the equatorward boundary at midnight in their model is located between $62^{\circ}$ apex latitude (strong activity) and $66^{\circ}$ (weak activity). However, their activity range ends at $E_{\mathrm{M}}$ ' values of 20 to 25 units (their Figs. 6 and 7). Thus, the indications here of strong westward substorm electrojet currents at latitudes below $60^{\circ}$ for $E_{\mathrm{M}}>10 \mathrm{mV} / \mathrm{m}$ corresponding to $E_{\mathrm{M}}$ ' values above 30 are compatible with their model.

In their statistical work they consider a "memory effect" that implies some delay for the effects resulting from changes in the coupling parameter. They define (their Eq. (2)) a retarded parameter, $E_{\mathrm{M}}$ ", integrated over $3 \mathrm{~h}$ up to the time in question using exponential weighting of $E_{\mathrm{M}}$ ' values with a time constant of $0.5 \mathrm{~h}$. This procedure corresponds roughly to imposing a delay of 1-1.5 h from a sudden change in the coupling parameter to its effect of having the auroral oval moved to its final position. The coupling parameter is referred to the polar cap by an intrinsic delay of $30 \mathrm{~min}$ (their Fig. 5) from values derived at the BSN position which is the same for the PC indices.

Thus, the retarding effect of $1.0-1.5 \mathrm{~h}$ in the general movements of the position of the auroral oval in the Xiong \& Lühr (2014) model is compatible with the delay of 2-3 h for the large displacements of the substorm auroral electrojets in the midnight auroral oval region in the cases of the sustained large PCN values considered here.

\section{GIC forecast relevance}

An important part of any forecast system is the amount of false alarms. Figure 10a illustrates by bars in blue, red, and black the number of cases each year on the left scale where the conditions $\mathrm{PCN}>10,15$, and $20 \mathrm{mV} / \mathrm{m}$, respectively, are met throughout one hour (60 consecutive minutes). The cases of $\mathrm{HV}$ power line disruptions in Sweden are shown by the black triangles at the time axis. The drawing of sunspot numbers referring to the right scale has been added for illustration of the relevant solar activity. It is seen that the number of cases of sustained large PCN values are largest at but not limited to solar maximum intervals.

In Figure $10 \mathrm{~b}$ the interval of PCN index values above the noted levels has been extended to $2 \mathrm{~h}$ (120 consecutive minutes). All HV line disruptions are still associated with the condition PCN $>10 \mathrm{mV} / \mathrm{m}$ throughout the $2 \mathrm{~h}$ interval.

In Figure 10c the interval of consistent PCN index values above noted levels has been extended to $3 \mathrm{~h}$ (180 min). One disrupt case (8 February 1986) is now left without indication of PCN $>10 \mathrm{mV} / \mathrm{m}$ throughout the $3 \mathrm{~h}$ interval.

Thus, the sequence suggests that "GIC alert" might be issued when PCN $>10 \mathrm{mV} / \mathrm{m}$ for more the $1 \mathrm{~h}$ and turned into "red alert" when PCN > $10 \mathrm{mV} / \mathrm{m}$ through more than $2 \mathrm{~h}$. In most years there would not be any alarm.

\section{General forecast of violent substorms}

The PC indices might also be used in general forecasts of strong substorms at subauroral latitudes. Most substorms, fortunately, are not causing power grid disruptions, but they may still cause disturbances related to fast magnetic variations anyway. The problems may be more relevant at latitudes lower than the usual auroral latitudes due to the increasing amount of
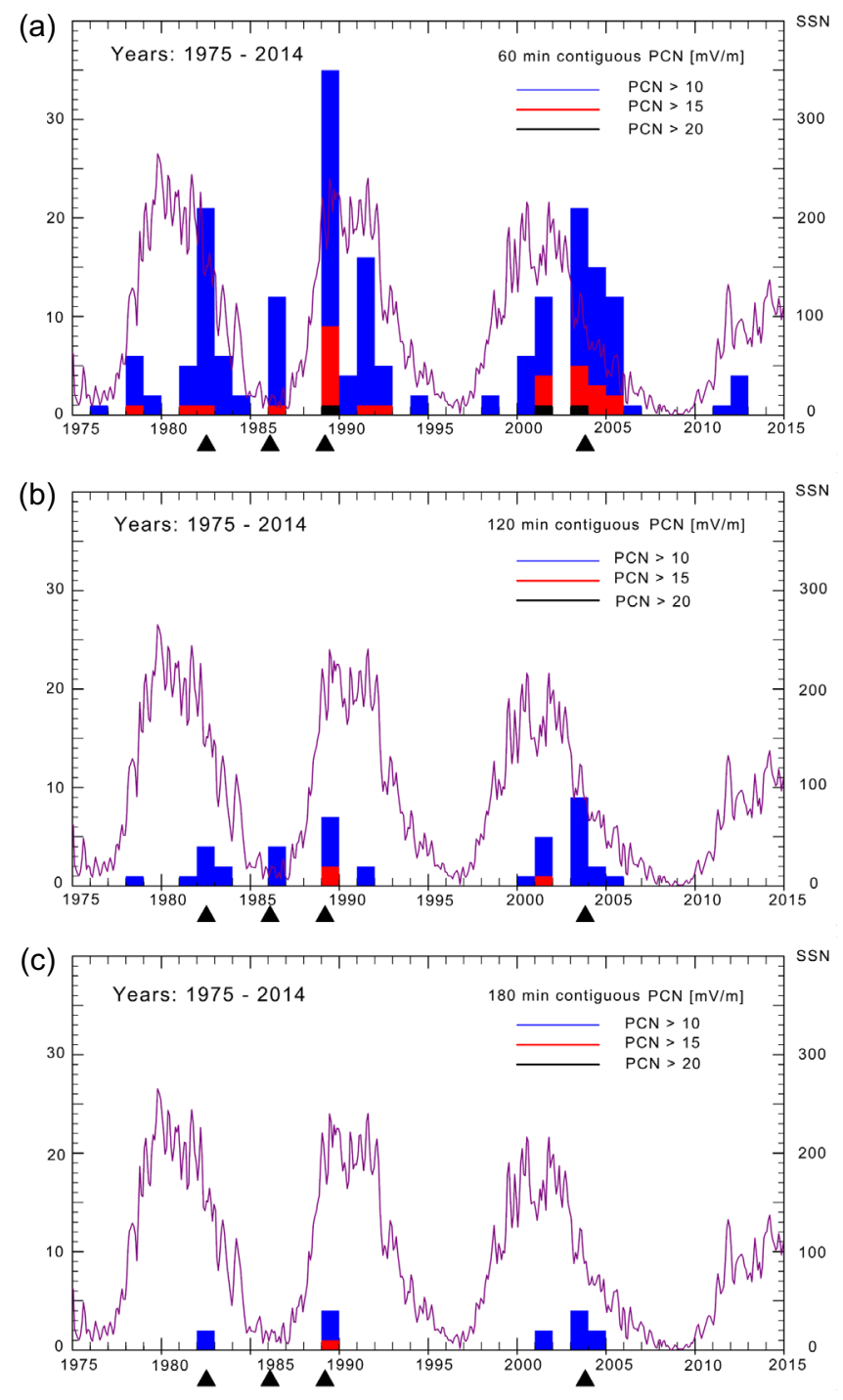

Fig. 10. (a) Yearly number of cases with $\mathrm{PCN}>10,15$, and $20 \mathrm{mV} / \mathrm{m}$, respectively, throughout $60 \mathrm{~min}$. Sunspot numbers added. (b) Interval extended to $120 \mathrm{~min}$. (c) Interval extended to $180 \mathrm{~min}$.

vulnerable technical installations further equatorward. An extended discussion on the distribution of $\mathrm{d} H / \mathrm{d} t$ values is provided in Stauning (2013b)

From geomagnetic measurements at the two sub-auroral locations Lövö (inv. lat. $=56.40^{\circ}$ ) during 1982-2003 and Uppsala (inv. lat. $=57.00^{\circ}$ ) during 2004-2016, all transitions between 1-min samples have been examined and the $\mathrm{d} H / \mathrm{d} t$ gradients in the horizontal component have been calculated counting only cases separated by more than \pm 4 h (i.e., in separate 8 -h time slots).

For each case of a $\mathrm{d} H / \mathrm{d} t$ value above levels of 5.0, 2.5, and $1.0 \mathrm{nT} / \mathrm{s}$, respectively, the values of the Polar Cap index (PCN) were derived through intervals of $4 \mathrm{~h}$ before to $4 \mathrm{~h}$ after the transitions. The 8-h total stretches were subdivided in 30-min intervals for each of which the mean and the median PCN values were calculated and plotted in Figures $11 \mathrm{a}-11 \mathrm{c}$ in the format of Figure 3. Standard deviations for the median values are shown by error bars at the middle of the 30-min intervals. 
(a)

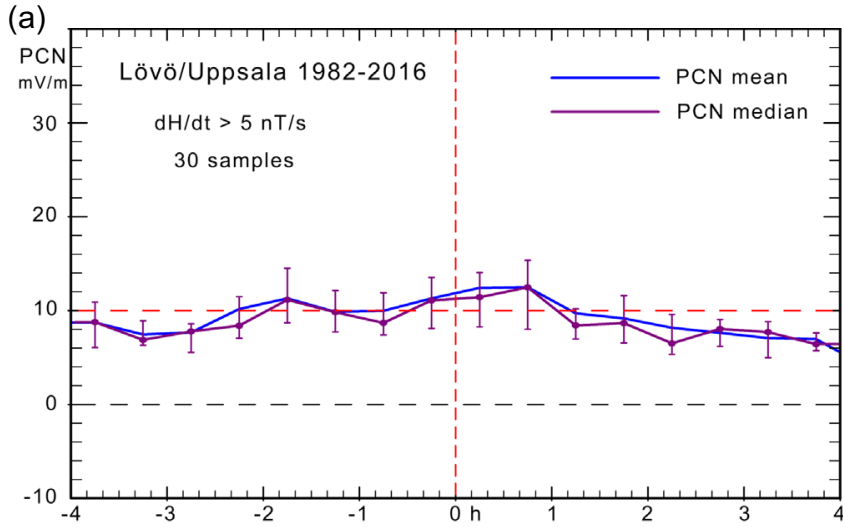

(b)

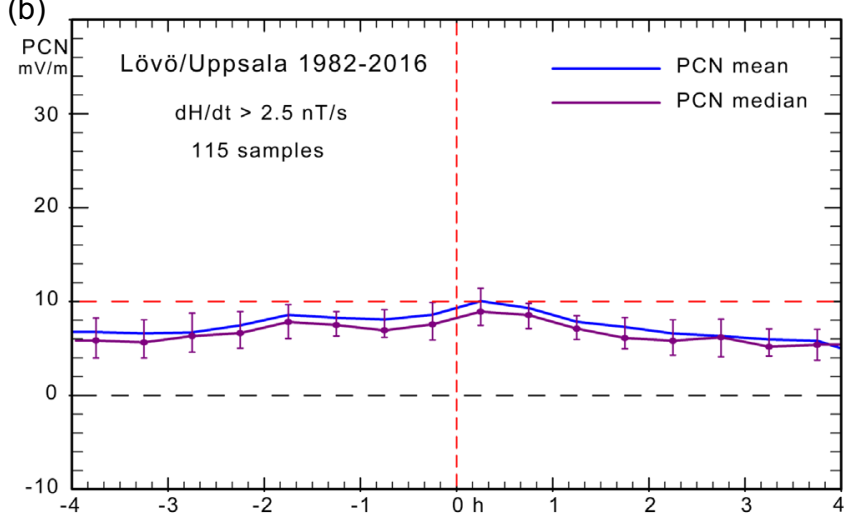

(c)

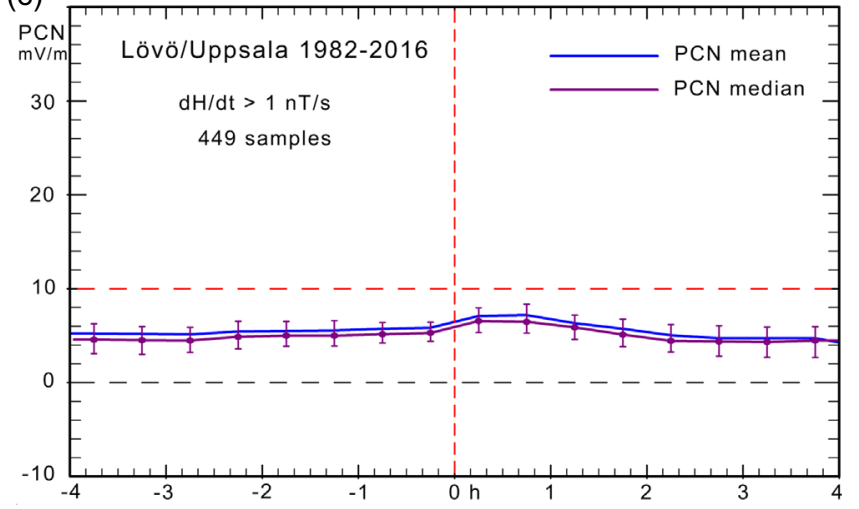

Fig. 11. Occurrences at subauroral latitudes of substorms with steep gradients vs. PCN index.

From Figures $11 \mathrm{a}-11 \mathrm{c}$ it is seen that the $2-4 \mathrm{~h}$ pre-event average PCN levels needed to generate substorm magnetic gradients greater than 1.0, 2.5, and $5 \mathrm{nT} / \mathrm{s}$, respectively, increases from 5 through 8 to $10 \mathrm{mV} / \mathrm{m}$. Exceeding the level $\mathrm{d} H / \mathrm{d} t=5$ $\mathrm{nT}$ used for Figure 11a is indicative of quite strong substorm events. Thus, with improved statistics due to the larger number of cases, the progression in $\mathrm{d} H / \mathrm{d} t$ values with increasing PCN levels is seen clearly in Figures 11a-11c. This progression supports the inference from Figure 3 that an alert level of $\mathrm{PCN} \approx>10 \mathrm{mV} / \mathrm{m}$ maintained through $2-3 \mathrm{~h}$ is the prerequisite for $\mathrm{HV}$ power line disruptions, which are usually associated with subauroral substorm gradients of $\mathrm{d} H / \mathrm{d} t>10 \mathrm{nT} / \mathrm{s}$.

It is seen from Figures $11 \mathrm{a}-11 \mathrm{c}$ that substorms with less violent variations than those of the stormy events that caused HV power line disruptions (cf. Fig. 3) are also preceded by
2-4 h intervals of persistent high PC index levels, which, most likely, are related to the need for consistent strong transpolar convection to generate equatorward displacements of substorms to subauroral latitudes.

This feature enables the use of the PC indices in general space weather forecast services jointly with further groundbased activity indicators such as the auroral electrojet indices as a supplement to consolidate forecasts based on measurements from satellites in the solar wind, e.g., at the L1 position. It should be mentioned again that vital satellite instruments could be disabled by hard radiation particularly at the starting phase of storm events such as those listed in Table 1. The measurements could also be affected by violent variability in the solar wind medium. In such cases the forecasts are hampered by the risk of issuing incorrect status descriptions or false predictions if the space weather monitoring relies on satellite-based data only.

An added yield from the present investigation of supersubstorms is the experience that neither the standard auroral electrojet indices based on measurements from an array of 12 observatories located within the auroral zone nor the SuperMag indices based on an extended array of observatories provide adequate monitoring of substorm activities in these extreme cases, where the region of strongest auroral activity has been displaced equatorward.

\section{Summary}

In most cases, strong substorms with fast variations would not occur immediately after the encounter of enhancements in the solar wind merging electric field to the front of the magnetosphere. Enhanced merging at the front of the magnetosphere would in the first step lead to enhanced transpolar convection of plasma with embedded magnetic fields over the polar caps into the tail region. When the transpolar convection generated by merging processes at the front dominates over the return flow at auroral regions arising from reconnection processes in the tail region then energy would be stored in the tail configuration. The magnetically open polar caps would be enlarged such that the auroral regions at their borders would be displaced towards lower latitudes.

These processes are counteracted by possible substorm activity that may enhance the unloading of accumulated tail energy, reduce polar cap extents and restore the positions of the auroral regions. For the strongest of the recorded cases the processes of loading the tail region and displacing substorm electrojet activities to subauroral latitudes may last for $2-3 \mathrm{~h}$ with consistently elevated PC index values. Subsequently, the accumulated solar wind energy could be released in substorms violent enough and at low enough latitudes to threaten important power grids by their related GICs. These relations form the basis for the potential use of the PC indices, when available in real-time, for space weather monitoring and forecast services.

\section{Conclusions}

- Real time PC indices could provide predictions of violent substorms that may harm power grids. It appears that PC index values remaining at or above an alert level of 
$10 \mathrm{mV} / \mathrm{m}$ throughout an interval of $2-4 \mathrm{~h}$ is the prerequisite for occurrences of fast magnetic variations $(\mathrm{d} H / \mathrm{d} t>10 \mathrm{nT} / \mathrm{s})$ at latitudes low enough $\left(<60^{\circ}\right)$ to harm vital power grids by the related GICs.

- The PCN indices could be based on magnetic data from either Qaanaaq (Thule) or Resolute Bay, preferably from both sources for added availability. PCN values could eventually be supplemented by PCS index values based on magnetic data from Vostok or Dome-C in Antarctica for added reliability and for forming the more representative combined Polar Cap index (PCC).

- PC index values maintained at values above $10 \mathrm{mV} / \mathrm{m}$ (alert level) throughout $1 \mathrm{~h}$ might initiate forecasts of substorm onset 2-3 h ahead in the night sector of subauroral regions with risk of strong GICs in vulnerable power grids. PC index values maintained above $10 \mathrm{mV} / \mathrm{m}$ for more than $2 \mathrm{~h}$ might initiate forecasts of imminent onsets of violent substorms with grave risk of very strong GICs in subauroral power grids.

- The amount of alert cases with PC > $10 \mathrm{mV} / \mathrm{m}$ maintained throughout one or more hours, is fairly small (few false alarms). In most years there would probably be none.

- For space weather applications it is suggested to build the real-time PC index derivation on direct access to the magnetic data. A scheme for real-time PC index calculations is available in the appendix of Stauning (2018c).

\section{Data availability}

Geomagnetic data from Qaanaaq for the PCN index and from 42 additional observatories in Northern Europe as well as data from 39 observatories in the North American region for surveys of disturbance conditions were supplied in part from the INTERMAGNET data service at http://intermagnet.org, in part from the DTU Space ftp data server at ftp://ftp.space.dtu. $\mathrm{dk} / \mathrm{WDC} /$, in part from the WDC service for Geomagnetism, Edinburgh, available at http://www.bgs.ac.uk, and in part from the Geophysical Department of University of Troms $\varnothing$ at http:// www.tgo.uit.no.

Data for PCN indices were provided by the magnetometers operated by DTU Space at the observatory in Qaanaaq managed by the Danish Meteorological Institute and from the observatory at Resolute Bay operated by the Geological Survey of Canada.

Data for PCS indices are supplied from the observatory in Vostok operated by the Arctic and Antarctic Research Institute (AARI) in St. Petersburg, Russia, and from the Dome-C observatory managed by Ecole et Observatoire des Sciences de la Terre (France) and Istituto Nazionale di Geofisica e Vulcanologia (Italy).

Solar wind OMNI BSN data from combined ACE, WIND, IMP8, and Geotail interplanetary satellite measurements were provided by the OMNIweb data service at Goddard Space Flight Center, NASA, and downloaded from http://omniweb. gsfc.nasa.gov.

Monthly sunspot numbers (v.2.0) were downloaded from WDC-SILSO, Royal Observatory of Belgium, Brussels at the portal http://sidc.be/silso/.

The PC index version used here is documented in the report SR-16-22 (Stauning, 2016) available at the DMI website:
http://www.dmi.dk/fileadmin/user_upload/Rapporter/TR/2016/ SR-16-22-PCindex.pdf. The report holds tables of PCN and PCS calibration parameters. A step-by-step procedure for calculation of real-time and final PC index values is available in the appendix of Stauning (2018c).

The standard auroral electrojet indices, AL, AU, AE, were supplied from WDC for Geomagnetism, Kyoto, AE index service at http://wdc.kugi.kyoto-u.jp, while the SuperMag auroral electrojet indices SMU and SML were supplied from the SuperMag project at http://supermag.jhu.apl.edu.

Acknowledgements. The staffs at the observatory in Qaanaaq (Thule) and at further observatories as well as their supporting institutes are gratefully acknowledged for providing the highquality geomagnetic data used here. The excellent service at the OMNIweb data centre at GSFC, NASA, to provide processed solar wind satellite data and the efficient provision of geomagnetic data from the INTERMAGNET and WDC data centres are greatly appreciated. The presentation has also benefited greatly from geomagnetic data supplied from the Geophysical Department of University of Troms $\varnothing$. The production and supply of the standard auroral electrojet and ring current indices indices at Kyoto WDC for Geomagnetism and the extended electrojet indices made available by the SuperMag project are strongly appreciated. Sunspot numbers were provided by WDC-SILSO, Royal Observatory of Belgium, Brussels. The author gratefully acknowledges the collaboration and many rewarding discussions with Drs. O. A. Troshichev and A. S. Janzhura at the Arctic and Antarctic Research Institute in St. Petersburg, Russia.

The editor thanks two anonymous referees for their assistance in evaluating this paper.

\section{References}

Baker DN. 2005. Specifying and forecasting space weather threats to human technology. In: Effects of space weather on technology infrastructure, Daglis I (Ed.), Springer, The Netherlands, Dordrecht. https://doi.org/10.1007/1-4020-2754-0.

Dungey JW. 1961. Interplanetary magnetic field and the auroral zones. Phys Rev Lett 6: 47-48. https://doi.org/10.1103/ PhysRevLett.6.47.

Cowley SWH. 2000. Magnetosphere-ionosphere interactions: a tutorial review. In: Magnetospheric current systems. Ohtani S-I, Fujii R, Hesse M, Lysak RL (Eds.), Geophysical Monographs 118, AGU, Washington DC, pp. 91-106. https://doi.org/10.1029/ GM118p0091

Gjerloev JW. 2012. The SuperMag data processing technique. $J$ Geophys Res 117: A09213. https://doi.org/10.1029/ 2012JA017683.

Gjerloev JW, Hoffman RA. 2014. The large-scale current system during auroral substorms. J Geophys Res Space Phys 119: 45914606. https://doi.org/10.1002/2013JA019176.

Janzhura AS, Troshichev OA. 2011. Identification of the IMF sector structure in near-real time by ground magnetic data. Ann Geophys 29: 1491-1500. https://doi.org/10.5194/angeo-29-14912011.

Janzhura AS, Troshichev OA, Stauning P. 2007. Unified PC indices: Relation to the isolated magnetic substorms. J Geophys Res 112 A09207. https://doi.org/10.1029/2006JA012132. 
Kamide Y, Kokubun S, Bargatze LF, Frank LA. 1999. The size of the polar cap as an indicator of substorm energy. Phys Chem Earth Part C: Sol Terr Planet Sci 24(1-3): 119-127. https://doi.org/ 10.1016/S1464-1917(98)00018-X.

Kan JR, Lee LC. 1979. Energy coupling function and solar windmagnetosphere dynamo. Geophys Res Lett 6(7): 577-580. https://doi.org/10.1029/GL006i007p00577.

Kappenman J. 2010. Geomagnetic storms and their impact on the U.S. power grid. Metatech Report, Meta-R-319, p. 197.

Lühr H, Huang T, Wing S, Kervalishvili G, Rauberg J, Korth H. 2016. Filamentary field-aligned currents at the polar cap region during northward interplanetary magnetic field derived with the Swarm constellation. Ann Geophys 34: 901-915. https://doi.org/ 10.5194/angeo-34-901-2016.

Newell PT, Sotirelis T, Liou K, Meng C-I, Rich FJ. 2007. A nearly universal solar wind-magnetosphere coupling function inferred from 10 magnetospheric state variables. J Geophys Res 112: A01206. https://doi.org/10.1029/2006JA012015.

Popov VA, Papitashvili VO, Watermann JF. 2001. Modeling of equivalent ionospheric currents from meridian magnetometer chain data. Earth Planets Space 53: 129-137. https://doi.org/ 10.1186/BF03352370.

Radasky WA, Kappenman JG. 2010. Impact of geomagnetic storms on EHV and UHV power grids. pp. 695-698. https://doi.org/ 10.1109/APEMC.2010.5475523.

Stauning P. 2007. A new index for the interplanetary merging electric field and the global geomagnetic activity: Application of the unified Polar Cap (PCN and PCS) indices. AGU Space Weather 5: S09001. https://doi.org/10.1029/2007SW000311.

Stauning P. 2011. Determination of the quiet daily geomagnetic variations for polar regions. J Atmos Sol Terr Phys 73: 2314-2330. https://doi.org/10.1016/j.jastp.2011.07.004.

Stauning P. 2013a. Comments on quiet daily variation derivation in "Identification of the IMF sector structure in near-real time by ground magnetic data" by Janzhura and Troshichev (2011). Ann Geophys 31: 1221-1225. https://doi.org/10.5194/angeo-31-1221-2013.

Stauning P. 2013b. Power grid disturbances and polar cap index during geomagnetic storms. J. Space Weather Space Clim 3: A22. https://doi.org/10.1051/swsc/2013044.

Stauning P. 2016. The Polar Cap (PC) index: derivation procedures and quality control. DMI Scientific Report SR-16-22. Available at: http://www.dmi.dk/fileadmin/user_upload/Rapporter/TR/2016/SR16-22-PCindex.pdf.

Stauning P. 2018a. A critical note on the IAGA-endorsed Polar Cap (PC) indices: excessive excursions in the real-time index values. Ann Geophys 36: 621-631. https://doi.org/10.5194/angeo-36-621-2018.

Stauning P. 2018b. Multi-station basis for Polar Cap (PC) indices: ensuring credibility and operational reliability. J Space Weather Space Clim 8: A07. https://doi.org/10.1051/swsc/2017036.
Stauning P. 2018c. Reliable Polar Cap (PC) indices for space weather monitoring and forecast. J Space Weather Space Clim 8: A49. https://doi.org/10.1051/swsc/2018031.

Stauning $\mathrm{P}$, Christiansen F, Watermann JF, Christensen T, Rasmussen O. 2002. Mapping of field-aligned current patterns during northward IMF. In: First CHAMP mission results for gravity, magnetic and atmospheric studies. Reigber C, Lühr $\mathrm{H}$, Schwintzer P (Eds.) Springer-Verlag, Berlin. ISBN 3-540-00206-5. https://doi.org/10.1007/978-3-540-38366-6_51.

Stauning P, Troshichev OA, Janzhura AS. 2008. The Polar Cap (PC) index. Relations to solar wind parameters and global magnetic activity level. J Atmos Sol Terr Phys 70(18): 2246-2261. https://doi.org/10.1016/j.jastp.2008.09.028.

Troshichev OA, Janzhura AS. 2009. Relationship between the PC and $\mathrm{AL}$ indices during repetitive bay-like magnetic disturbances in the auroral zone. J Atmos Sol Terr Phys 71(12): 1340-1352. https://doi.org/10.1016/j.jastp.2009.05.017.

Troshichev OA, Andrezen VG, Vennerstrøm S, Friis-Christensen E. 1988. Magnetic activity in the polar cap - A new index. Planet Space Sci 36(11): 1095-1102. https://doi.org/10.1016/0032-0633 (88)90063-3.

Troshichev OA, Janzhura AS, Stauning P. 2006. Unified PCN and PCS indices: method of calculation, physical sense and dependence on the IMF azimuthal and northward components. J Geophys Res 111: A05208. https://doi.org/10.1029/2005JA011402. (note correction in Troshichev et al., 2009).

Troshichev OA, Janzhura AS, Stauning P. 2009. Correction to "Unified PCN and PCS indices: Method of calculation, physical sense, and dependence on the IMF azimuthal and northward components". J Geophys Res 114: A11202. https://doi.org/ 10.1029/2009JA014937.

Troshichev OA, Podorozhkina NA, Sormakov DA, Janzhura AS. 2014. PC index as a proxy of the solar wind energy that entered into the magnetosphere: 1. Development of magnetic substorms. J Geophys Res Space Phys 119: https://doi.org/10.1002/ 2014JA019940.

Xiong C, Lühr H. 2014. An empirical model of the auroral oval derived from CHAMP field-aligned current signatures - Part 2. Ann Geophys 32: 623-631. https://doi.org/10.5194/angeo-32-6232014.

Xiong C, Lühr H, Wang H, Johnsen MG. 2014. Determining the boundaries of the auroral oval from CHAMP field-aligned current signatures - Part 1. Ann Geophys 32: 609-622. https://doi.org/ 10.5194/angeo-32-609-2014.

Walach M-T, Milan SE, Yeoman TK, Hubert BA, Hairston MR. 2017. Testing nowcasts of the ionospheric convection from the expanding and contracting polar cap model. Space Weather 15. https://doi.org/10.1002/2017SW001615.

Cite this article as: Stauning P. 2020. Using PC indices to predict violent GIC events threateningpower grids. J. Space Weather Space Clim. 10, 3 . 